\title{
"If the Big Fish are Doing It Then Why Not Me Down Here?": Informal Fee Payments and Reproductive Health Care Provider Motivation in Kenya
}

\author{
Katherine Tumlinson (iD), Margaret W. Gichane, and Siân L. Curtis
}

\begin{abstract}
Informal fees are payments made by patients to their health care provider that are over and above the official cost of services. Payments may be motivated by a combination of factors such as low supervision, weak sanctions, and inadequate provider salaries. The practice of soliciting informal fees from patients may result in restricted access to medical care and reduced care-seeking behavior among vulnerable populations. The objective of this study is to examine nuanced health care provider perspectives on informal fee payments solicited from reproductive health patients in Kenya. We conducted in-depth semistructured interviews in 2015-2016 among a sample of 20 public and private-sector Kenyan health care workers. Interviews were coded and analyzed using an iterative thematic approach. More than half of participants reported that solicitation of informal fees is common practice in health care facilities. Providers reported low public-sector wages were a primary driver of informal fee solicitation coupled with collusion among senior staff. Additionally, patients may be unaware that they are being asked to pay more than the official cost of services. Strategies for reducing this behavior include more adequate and timely remuneration within the public sector, educating patient populations of free or low-cost services, and evidence-based methods to increase provider motivation.
\end{abstract}

\section{INTRODUCTION}

$\int$ nformal payments-defined as patient provision of payments to health care providers in excess of sanctioned fees-have been well-documented in low- and middle-income countries (LMICs) (Lewis 2007). Studies demonstrate the ubiquitous nature of the behavior across a range of health care settings and with different levels of medical staff (i.e.,

Katherine Tumlinson is a Faculty Fellow of the Carolina Population Center and an Assistant Professor, Department of Maternal and Child Health, Gillings School of Global Public Health, University of North Carolina at Chapel Hill, 135 Dauer Drive, 405a Rosenau Hall, CB \#7445, Chapel Hill, NC 27599-7445. Email: ktumlin@email.unc.edu. Margaret Gichane is a postdoctoral researcher at Research Triangle Institute International, Research Triangle Park, NC. Siân L. Curtis is a Faculty Fellow of the Carolina Population Center and an Associate Professor, Department of Maternal and Child Health, Gillings School of Global Public Health, University of North Carolina at Chapel Hill, NC. 
doctors, nurses, clinical workers) (Balabanova and McKee 2002; Killingsworth et al. 1999; Lindkvist 2013; Maestad and Mwisongo 2011; McPake et al. 1999; Moldovan and Van de Walle 2013; Stringhini et al. 2009).

Informal payments come in many forms. Providers and patients report witnessing the provision of cash payments or material items for: services or commodities that are supposed to be free, marked up prices for treatments, bypassing long lines, and improved quality and access to care (Balabanova and McKee 2002; Ensor 2004; Gaal et al. 2006; Killingsworth et al. 1999; Maestad and Mwisongo 2011). In some cases, more covert methods of solicitation occur such as clinicians recommending a patient seek care in the private facility where they also practice (Lindelow and Serneels 2006; Stringhini et al. 2009) or clinicians running private dispensaries and encouraging patients to purchase medications from them rather than the health facility (Lindelow and Serneels 2006; Stringhini et al. 2009). Informal payments can be very burdensome and restrictive for patients, leading some to refrain from seeking care (McPake et al. 1999; Killingsworth et al. 1999). In a study conducted in health facilities in Bangladesh, researchers found that patients paid nearly 12 times the amount for unofficial fees as compared to sanctioned fees (Killingsworth et al. 1999). Fees may be solicited from patients during multiple points of care. In one account, a patient described fees being solicited to pay for registration, medical supplies, kind treatment and attention from nurses, and for necessary drugs (McPake et al. 1999).

It is important to note that patients sometimes volunteer informal fees as a sign of appreciation for good care they received or as a means to secure better care (Maestad and Mwisongo 2011; Moldovan and Van de Walle 2013). Clinicians report that some patients who give them informal payments feel entitled to their care and have higher expectations (Stringhini et al. 2009). Thus, a two-tier system of health care service delivery is instituted wherein those who can afford to pay the fees receive care that is more expedient, of higher quality, and inclusive of necessary services or treatments (Killingsworth et al. 1999; Lindkvist 2013; Maestad and Mwisongo 2011; McPake et al. 1999).

Across LMICs, the provision of informal payments is often attributed to structural issues in the health care system, the most prominent of which is low health care worker salaries. Health workers report receiving salaries that are not commensurate to their time and experience. Those working in the public sector report that their salaries have not kept up with inflation and are not sufficient to cover their needs (Chandler et al. 2009; Lindelow and Serneels 2006). For some, solicitation of informal payments is considered a means of survival (Ensor 2004). Another driving factor is the lack of punishment for the solicitation of informal payments. Health care workers describe corruption at varying ranks within the health care facility (Stringhini et al. 2009). Different cadres of health care workers may work together to solicit informal payments and share some of their earnings (Maestad and Mwisongo 2011). The collusion of health care workers in this practice may restrict those not engaging in the practice from stepping forward to report their peers.

A critical gap in the literature on informal payments is the analysis of the practice within the context of family planning services. Little is known about whether a system of informal fees impacts family planning use within the context of Kenya, a country whose government has formally recognized family planning as a critical component of reduced population growth and sustainable development. Kenya is committed to increasing overall contraceptive 
use over the next decade, with a special emphasis on vulnerable populations such as adolescent women, of which currently only 40 percent are using any form of contraception (Government of Kenya 2017). These commitments were initially formalized at the 2012 London Summit on Family Planning and updated in 2017. Emergent literature suggests that the solicitation of informal fees occurs when women seek out family planning methods. Utilizing the simulated client method, Tumlinson et al. (2013) found that the majority of simulated clients were charged higher fees than official prices for oral contraceptive pills in clinics in Kisumu, Kenya. A report from the Kenyan Federation of Women Lawyers revealed that women who were unable to pay unofficial fees for family planning methods were often made to wait for longer periods, or even ignored completely (Center for Reproductive Rights and Federation of Women Lawyers-Kenya 2007).

Although several prior studies conducted in east Africa have identified underlying structural factors that facilitate solicitation of illicit fees by health care workers, little investigation of informal payments has been conducted in Kenya. Although prior studies conducted by Tumlinson et al. (2013) and the Center for Reproductive Rights and Federation of Women Lawyers (2007) suggest the practice may be widespread, little is known about the key contributing factors. Reducing informal payment solicitation requires an in-depth understanding of the context and nature of the behavior from those on the frontlines of service delivery. The aim of the present study is to explore health care provider perceptions on the scope and determinants of soliciting informal fees payments for family planning services in Kenyan health care facilities. We also sought to examine provider recommendations for curbing the behavior.

\section{METHODS}

\section{Recruitment}

Participants were recruited via a purposive chain referral approach. The two initial seed participants were selected based on their extensive experience with health care provision in the two study sites and a prior relationship with the study principle investigator (PI; first author). Each of these participants, and subsequent recruited participants, referred the PI to additional study participants known to them who they believed would be interested in participating. To be eligible for the study, participants had to be 18 years or older, proficient in English, and work in a health care facility that provides family planning services in Nairobi or Kisumu, Kenya. Doctors were necessarily excluded because they are not present in smaller facility types (dispensaries and health centers) and are not typically involved in family planning provision in the larger facilities where they practice. In this paper, we present data that are nested within a larger study on family planning quality of care; thus, the two study cities were selected based on their location in regions of Kenya with modern contraceptive prevalence rates similar to the national average (53 percent) (Kenya National Bureau of Statistics and ICF International 2015).

\section{Procedures}

In-depth semistructured interviews were conducted in English by the PI. The content of the interview guide was developed by the PI based on findings from a mystery client study 
conducted in Kisumu that revealed a number of negative provider behaviors (Tumlinson et al. 2013). The interview guide covered: provider absenteeism, informal payments, verbal abuse, provider motivation, and solutions to reduce facility barriers to contraceptives. Interviews ranged from 20 to 80 minutes and took place in a private location where participant responses could not be overhead. Providers received a small stipend to cover transportation; otherwise, they were not offered any incentive for their participation. Interviews were conducted between July 2015 and June 2016 in Central and Western, Kenya.

\section{Analysis}

In-depth interviews were audio recorded and transcribed verbatim. All transcriptions were checked for accuracy. Nvivo software version 11 was used for data management and analysis. Data analysis was conducted in an iterative and collaborative process informed by thematic analysis (Braun and Clarke 2006). Researchers read each interview and wrote analytic memos to immerse themselves in the data. An initial codebook was developed based on the emergent themes. A small sample of interviews were coded by researchers and discussed collectively to reconcile discrepancies and collapse codes. The remaining interviews were then independently coded. Final themes were compared within and across interviews. The data reported here are a subset of codes related to provider motivation and the scope, contributing factors, and implications of informal payments.

\section{Ethical Approval and Informed Consent}

Upon enrollment, all participants provided both verbal and written consent. Ethical approval for the study protocol was provided by both Princeton University and the Kenya Medical Research Institute. The data are available on request from the authors.

\section{RESULTS}

\section{Characterizing the Sample}

The final sample was composed of 20 participants, the majority of whom were female ( $\mathrm{n}$ $=16)$ and employed in public-sector health facilities $(\mathrm{n}=13)$. Most $(\mathrm{n}=15)$ were nurses or community health nurses. The other five respondents included: one clinical officer, two HIV testing and counseling (HTC) counselors, one health center information officer, and one community health worker. Participant experience in the health care field ranged from one to 21 years.

\section{Scope and Nature of Informal Fee Payments}

Of the 20 participating health care providers, 13 reported that the solicitation of informal fees is common practice within the facilities where they are currently or were formally employed, or that they have heard of this practice in other Kenyan facilities. Participants varied in their willingness to disclose observing the practice. In some cases, participants were initially hesitant to disclose observing provider solicitation of informal payments. However, most spoke freely about the behavior. In the following account, a participant describes observing the practice first-hand in the health care facilities they have been employed in: 
Yes, it really happens a lot when we are at work. Yeah, sometimes a patient comes and you know that you should be offering the service for free and some health care providers, being of that mentality, we have that, you know, at the end of it all, this patient has to pay something so that I get my transport from that place, despite the fact that you're being paid. (Nurse, private-sector, seven years of experience)

Other providers confirmed this account, with one participant noting they have seen this practice in almost every facility where they have worked.

Yes, it's quite common, even for services that's supposed to be free. It's sad but it happens. Almost in all the facilities that I've worked in, I've seen one-not everyone, of course-but one or two people always have had those types of things happen. (Nurse, nongovernmental organization [NGO], six years of experience)

Respondents described health care providers obtaining informal payments from patients in various ways. The most common modality for obtaining informal payments was by charging patients for medications or medical procedures that are supposed to be free based on clinic guidelines. In such instances, a provider may say that the medical supplies or a particular drug carry a fee, and that is the only way the patient's need can be met. However, several participants described some more covert methods that other providers used. There were descriptions of providers telling patients that the health facility was out of a certain free commodity, but that the provider could get the commodity for them from their own personal supply for an added fee. In reality, the provider did not have a personal supply but was simply selling the patient the free commodity.

Although most participants described scenarios in which informal payments were solicited from patients, there was one account of patients initiating the payment as a sign of gratitude:

But others will suggest, give appreciation without even-It's just a thank you. 'Take a couple of sodas after you do that...' We don't discourage. If somebody appreciates you, that one is fine. But you don't-they (the providers) are not supposed to demand (anything extra). (Nurse, public-sector, 13 years of experience)

The amount of money provided as an informal payment appears to vary depending on the service or commodities provided. Fees ranged from 50 shillings ( 0.49 USD) up to 3,000 shillings (29.17 USD) in one rare case. One participant described the extra charges for different family planning methods:

Well, for family planning services, if we have different methods, but for the long acting methods (of contraception), they would be charging even 500 shillings. If it is this injection Depo, maybe 50 shillings. But they are supposed to be free. (Nursing officer, public-sector, 10 years of experience) 
Some providers did not consider informal fee payments to be problematic if the provider is willing to forgo the fee in scenarios where they perceive the patient is not able to afford such payments:

Maybe you tell that client if you want me to do that dressing, you have to give some extra money. But it's not something that clients know ... But if somebody doesn't have, we do it. Yes, we don't send you away that you don't have because I know it's supposed to be free. (Nurse, public-sector, 10 years of experience)

\section{Contributing Factors}

\section{Individual-Level Factors}

At the individual level, participants primarily discussed inadequate wages as a motivation for soliciting informal fees from patients. The inadequacy of wages was discussed from two distinct viewpoints: inadequate for survival, and inadequate for the skill and effort required to manage large caseloads and challenging procedures.

Salaries Inadequate for Survival. Several providers indicated the wages paid to medical professionals are not adequate for survival and that it is difficult to provide for basic needs such as food and shelter on such a small salary.

So sometimes you get a peanut pay and back at home maybe you're a father of around three or four children-sometimes there are other dependents at home who also want assistance ... You end up just to see how you can survive, just through getting some money from your patient to get transport. Basically, that is what happens. People get money for patients so that at least you can get something for your transport, something for your lunch, something for your supper, something that is to sustain you when you're out of work. (Clinical officer, public-sector, 11 years of experience)

In some cases, delays in the start or continuation of the salary contribute to providers not having sufficient funds to survive. This occurrence was mentioned by staff in public-sector clinics where this is a big issue. Salary delays can be especially burdensome when they last extended periods of time:

They're paid some lateness of salaries. Maybe you find you're broke. They come, okay, maybe today I'll just charge, because I don't have transport back home. I'll just have to charge to clients. Maybe I'll get 100 shillings. I'll get transport back, and tomorrow back to work. Today, I'll just have to charge. My salary is delayed for maybe a month, a month and a half. (HTC counselor, public-sector, six months experience)

Although participants agreed that this was a negative behavior, some expressed internal conflict in their perceptions of the behavior. This participant describes the tension faced by providers who are trying to balance their own needs for survival against the harsh financial realities facing many of their patients: 
It becomes a challenge maybe for them to get money from those people. So the patient ends up trekking, walking, a long distance and maybe has given out the money to get the healthcare worker. And this healthcare worker is someone who is earning salary. So sometimes it doesn't look well. Though we also don't like it ... Sometimes you earn salary but is small and you also need something for your stomach. You need to survive. (Clinical officer, public-sector, 11 years of experience)

A number of providers suggested provider wages are sufficient for the most basic survival but do not allow for participation in educational opportunities or home ownership.

On the other side also, sometime people go getting loans maybe to go to school and getting loans would be to buy a piece of land. And so at the end of the day maybe that salary ... sort of when it comes to deductions you're left with not so much money. (Nursing officer, public-sector, 10 years of experience)

These reflections indicate a desire on the part of health care providers to feel less financially insecure and more fiscally comfortable.

Salaries Inadequate for the Skill and Effort Required. A number of participants highlighted the difficult nature of their work, which requires skill and training and a willingness to engage in "donkey work," that is, excessively difficult and/or menial tasks. In the following communication, a provider describes that the pay is enough for survival but does not reflect the skill and effort required of their job.

... the nurse for example, they are seriously poorly paid versus the workload, there's no single facility that I know that they do the ratio that is recommended. It would be usual for (the ratio of) a nurse or healthcare provider to a patient is four times more than what is expected. (Nurse, NGO, six years of experience)

These government facilities employees, basically you know what people are being paid. I can say it's not commensurate to the quality of work that they do. They get peanut. The pay is quite small anyway. (Clinical officer, public-sector, 11 years of experience)

A lower cadre participant conveyed the responses of a colleague that she once questioned about the practice of soliciting informal fees. The colleague's response, described below, conveys a desire for compensation that reflects the difficulty of the work required:

Actually, I don't understand why they always do that. Yeah, I once asked a clinician and, and she told me that they're doing a lot of work, and let's say like family planning thing, removing that thing (the contraceptive implant) is not nice, so that can't do it for free. They're doing a lot of work, they're straining a lot so just can't be for free .... it's not appealing, it's hard, so she just-she told me that you can't do that for free. (HTC counselor, public-sector, one year of experience) 


\section{Structural-Level Factors}

In addition to concerns over the adequacy of wages, a number of structural factors exist that help to facilitate the practice of health care providers soliciting informal fees from patients. These factors include a patient population that lacks knowledge and feedback mechanisms, a system in which senior staff often collude in the practice of soliciting informal fees, a national medical admissions process that matriculates and graduates cohorts of health care providers who lack a sense of professional identity, health care facility sector and size, and managerial policies.

Patient Population Lacks Knowledge. A few participants noted that patients may be charged informal fees because they are unaware of what services they are entitled to free of charge. Lack of information was considered to be an issue in rural areas and among more vulnerable populations. One participant described how there are notices listing the cost of services, however, this is not accessible to all:

But for a few people, the illiterate ones won't see. They won't read. You even try writing in my mother tongue, Luo, they can't read. You just get in, you pay the 100 or 50 shillings. At the end of the day when you're asked by my in charge [supervisor] ... you paid, but didn't you see the notice? I can't read. So you see, at the end of the day, you find yourself paying. (HTC counselor, public-sector, six months experience)

Although extension agents often carry a mandate to share this information with communities, this participant describes community health workers who are reluctant to demoralize patients and anger providers:

We have community health workers, community health extension workers who work-who are actually employed in the community, work in the community, they help in providing this information, but their work is futile. When the patient comes to the facility and maybe the community health worker told them that these drugs they're supposed to get for free, again they (the patients) come to the facility and they pay, they get demoralized. So, they (the community health workers) rather not go back and tell the community members that they're supposed to get the drugs for free because the healthcare provider would look at him in a certain way that you are infringing on, on my service. (Nurse, privatesector, seven years of experience)

Senior Staff Often Collude in the Practice of Soliciting Informal Fees. A number of providers discussed the challenge of stopping informal fee payments given the high prevalence of senior medical staff engaged in the practice. Participants suggest higher level staff are not only aware of the practice, but also participate:

It's happening and the boss himself knows it's happening, and it's-for now it's like a trend that-with services like typhoid, you have to pay, yeah, it's a must. It's something there. I joined that facility when it was happening and the boss is aware, yes ... They're eating together ... At times, I do keep myself busy and 
leave the facility a bit late. So, you just spot them, they go to a certain corner, a certain room and they say, today we made this cash and they split it among themselves. (HTC coordinator, public-sector, one year of experience)

Participants suggested the participation of senior staff in the practice of capturing informal payments makes it difficult to discourage or prevent this behavior among lower-cadre staff, as one public-sector nurse with 10 years of experience notes, "If the big fish are doing it then why not me down here?" This sentiment is echoed by another public-sector nurse with seven years of experience:

If a person at the top eats, you know, it's actually difficult telling a person at the bottom end, stop eating.

Family Pressure and Medical Admissions Practices do not Account for Professional Identity. Finally, several participants discussed the role of family pressure in forcing people into the medical profession, regardless of whether or not they have a propensity for working as a doctor or nurse. One female public-sector nurse with five years of experience described how the current economy in Kenya may prevent even those who are well-educated from finding employment immediately upon graduation. The uncertainty around postgraduation employment and the need to 'hustle' for work is a source of anxiety for many parents. As a result, parents may attempt to steer their children into medical or nursing school in order to safe-guard their opportunities for immediate postgraduation employment, "They want to, when you are through with your college, you get job direct instead of hustling a lot." Others confirm this practice:

They want a better future for you, so if they think nursing will give you a better future, then they kind of encourage you to do nursing ... if you don't, then they are not paying your school fees. (Community health nurse, private-sector, 3.5 years of experience)

A couple of participants also described how those with a strong desire to work in health care delivery may be thwarted by poor grades or a lack of resources. A private-sector nurse with four years of experience describes how only those students who earn high grades during post-secondary education are able to earn admission into medical or nursing school, conveying that these are not always the same people who have a passion for the work. Another participant (private sector nurse with 20 years of experience) suggested it is not possible to gain entry to medical or nursing school without paying a large fee. She suggests that the process of soliciting informal fees for school entry results in a matriculation mismatch where those selected into a medical occupation are often different from those with a strong professional identity for the provision of high quality health care, stating, "That's the bribe: 400,000 (Kenyan Shillings) and that one who really wants to become a nurse does not get an opportunity to become a nurse." The systemic family pressure, informal fee-for-entry, and high or rigid qualification requirements may, in combination, contribute to the opinion of another participant who suggests that those who ultimately enter the medical profession in Kenya often lack a desire to be in a helping profession: 
Okay, what I can say is some of the healthcare provider's (low) motivation comes from lack of interest in whatever they're doing. They went into that profession with the aim of making money, not with an aim of helping a client. It wasn't a call, it was actually a profession where they saw an opportunity to make money. (Nurse, private-sector, seven years of experience)

Facility Sector and Size. Solicitation of informal payments was described in both public and private-sector clinics. However, there was some agreement among participants that this practice is more likely to occur in government clinics and hospitals. One participant suggested the practice of informal fee solicitation occurs more prevalently in public health care facilities because of lower public-sector wages combined with a lower potential for meaningful consequences if caught, stating:

So you hear that the workers who are employed in private facilities, it's become a bit difficult for them to ask for extra coin because of fear of maybe losing their jobs. But the government (public facilities) ..., basically you know what people are being paid ... And the money that you get from your salary is quite small and cannot sustain you properly at your home. So what you will have to do is get these clients and ask something from them." (Clinical officer, public-sector, 11 years of experience)

Additionally, facility size may influence solicitation of informal payments. One participant noted smaller facilities are not beholden to the same payment structures as larger county and regional hospitals. Consequently, providers in smaller facilities may feel like they have more flexibility in what they solicit from patients.

\section{Impact on Patients}

A number of study participants discussed the negative impact of informal payments on the care-seeking behavior of patients. Informal payments reportedly discourage service delivery in two primary ways. First, patients who lack the funds are not able to access services:

Another challenge that the mothers face, I must say, could also be sometime the mere fact that they don't have money ... This client will delay in coming to seek service ... By the time she comes to the facility when she has this money the provider will ask for probably it is too late, and that could have consequences. This lady wanted the (contraceptive) injection at this point when it would help prevent pregnancy, but because she doesn't have the 50 shillings she'll have to wait for a longer period, maybe two weeks. By the time she comes in, that unwanted pregnancy has set in, then, now she has to cope up with a burden which could have been prevented. (Nursing officer, public-sector, 10 years of experience)

Second, patients may become discouraged or demoralized when charged for services they understand should be free: 
Finding ways of getting more from the client will discourage even the clients who are coming for the services. The clients will not come for the services in the facility. (Nurse, public-sector, six years of experience)

\section{Provider Suggestions for Reducing Informal Fee Payments}

Participants offered several suggestions for reducing informal fee payments from patients to providers in the Kenyan health care system. The suggestions offered by providers fell into two broad categories: suggestions to empower patients and suggestions to better motivate health care providers.

\section{Patient Empowerment}

Community Education. Participants expressed a need to improve efforts to inform patients about the actual fees for services and empower them to use this information to hold providers accountable. Although some clinics have written notices, they are primarily written in English, which can exclude low-literacy patients and non-English speaking clients. Participants suggested alternative communication methods including radio or television announcements. One participant described how posters have been effective in her place of work:

$\mathbf{R}$ : Actually, if you come to us-most of the government facilities-you'll see posters used to warn the patients.

I: Do those posters help?

R: Yeah, they do. Because some ignore them-they'll find a way, 'This is for specific services,' but, yeah, it helps. Because the health providers tend to shy away because the patient challenges about the poster, yeah. So, yeah, they help. (Nurse, NGO, six years of experience)

Some participants provided examples of how collective community action can reduce provider solicitation of informal fees. Examples included communities organizing to remove physicians who were charging exorbitant fees. One participant described such a scenario:

So, you see, this thing (knowledge of a provider soliciting an informal fee) will circulate through the community and being the facilities within the communities, those who are working in the facilities also live in the community. So, even the management will hear, "That facility is not too good. If you go there, you'll be asked for money." So I think we should all harmonize and be sensitized because it's a community approach. It's not an individual approach; it's a community approach. If the community says, 'We don't want this stuff here,' you won't stay in that familiar facility. (Nurse, private-sector, four years of experience)

Feedback Systems and Visible Change. Participants also discussed the need for more reliable and actionable patient feedback systems. Several participants mentioned systems they perceived to be effective including disciplinary committees, feedback boxes, and an open channel of communication with a high-level staff person: 
Like in the hospital I work, when a client comes to work and her services are not met, we have a chairman. By the way this hospital, it's a community hospital. So there's a chairman who comes to the hospital almost weekly. So when the patients don't get their services correctly, they complain to the chairperson or the board of management of the hospital. So with that, the board gets to know who does what, who does not come to work, who sees patients nicely, who talks to patients rudely. So most health providers there, they kind of-they have good rapport with patients. (Health center information officer, nine months experience)

Participants cautioned that feedback systems must be taken seriously. There were some accounts of places where there were patient reporting channels that patients were hesitant to use. In order for a feedback system to be effective, one participant recommended that managerial responses be tied to visible changes at the facility level. Without visible changes, the participant warned that patients will stop giving feedback and give up hope that services will improve.

Giving feedback is one thing, 'cause other clients will tell you, "Well it is reported and nothing has happened." So, if they see something happening to the feedback, then probably they'll stop. They say they don't report because they'll not do anything anyway. (Community health nurse, three and a half years of experience)

\section{Provider Motivation}

Adequate Wages and Promotions. One of the most common suggestions from participants centered around increased compensation. Many providers felt that improving provider wages would reduce provider's dependence on informal payments to supplement their incomes. As was described earlier, many felt that low wages were a key reason providers ask patients for extra money. Improving salaries is one component of improving the work environment that may prevent providers from soliciting informal payments:

Yes, it can be stopped, and the only way to motivate them is to give them better working conditions, motivate them by paying them well, and employ more staff. If the work is too much, they can employ more staff. (Nurse midwife, privatesector, 21 years of experience)

Participants also sometimes noted the need for promotions to be enacted when due, with one public sector nurse with six years of experience noting, "You'll stay in that job for almost ten years before being promoted."

More Provider Education and Trainings, Distributed More Equitably. Providers also commonly discussed the important role of off-site training activities in helping providers to feel more motivated or passionate about their work. Trainings help stave off occupational boredom because providers are able to learn new information and techniques. Further, trainings can be a chance for providers to step away from the demands of service delivery and be reminded of the importance of customer care: 
Yeah, frequent trainings, frequent trainings. When they feel work is too much, they can, you know, with the trainings maybe for a week or two, just to refresh them on what is happening and customer care because these clients are our customers. Without them you don't put food on the table. (Nurse midwife, private-sector, 21 years of experience)

Several participants revealed that many providers look forward to the opportunity to participate in off-site trainings because, in addition to receiving new knowledge, they are also provided with food and lodging per diems. Such incentives made the providers feel appreciated for their work. However, the process for determining which providers are selected for off-site training is not transparent. As a result, this participant felt these opportunities most often go to those providers already favored by their manager and are rarely distributed in a fair manner.

Yeah, it's supposed to be fair. For example, maybe today I go for a training. Next time, maybe it should just be a list that goes around. Today, number one goes, the next month, the number two goes ... But sometimes you get that only one person is getting favored. And when the training comes, only one person is getting called. The rest is just doing their work. (Clinical officer, public-sector, 11 years of experience)

Attitude is Key. Although many participants gave one or more suggestions for reducing informal payments, these suggestions came with the realization that even increased wages and training opportunities will be insufficient if the strongest contributing factor-that of poor attitudes among health professionals-is not addressed. One provider (public-sector nurse, seven years of experience) hypothesized poor attitudes result from lack of empathy, that is, a failure to recognize patients as their "brothers and sisters back home." Poor attitudes were often described as a lack of dedication or general disinterest in the profession that results in the provision of substandard patient care:

But on the other side, providers also, they must look at the bigger picture because giving a client missing a quality family planning service and probably she has that need, and she stand back. You know, the implication is that this unwanted pregnancy that will occur. And the cost is big. So again it comes back to what do-what are our values. Do we know how these services help the people? Of course we know, but we just ignore. So I feel we providers-I don't know whether we'll have to (be) sensitized, to be reminded, or motivated but I think it comes down to individual values. (Nursing officer, public-sector, 10 years of experience)

A provider noted that opportunities to educate providers are a critical chance to change provider attitudes:

We first need to work on their attitude, because if you have a positive attitude toward your work, then you're likely to be motivated to work. So a change of attitude is kind of education, creating awareness, telling them the positive things 
about health care profession as a career. And to let them know that you're dealing with people's lives. It's not just about money or a job but saving lives. (Community health nurse, public-sector, three and a half years of experience)

\section{DISCUSSION}

The goal of this study was to gain a better understanding of the scope of informal payments within Kenyan health care facilities. We also sought to understand informal fee payments in terms of the factors that contribute to this practice, the patient impact, and potential areas for intervention. The 20 health care providers participating in this study provided diverse feedback on the overall scope of informal payments. Although the majority of participants reported the solicitation of informal fees from patients is common practice and problematic for many patients, some providers had no knowledge of these fees and others suggested this was mainly an issue of the past. This variation in beliefs around the commonality and acceptability of informal fee payments may reflect heterogeneity in personal values, exposures, and beliefs between individual providers. The variation may also reflect the ways in which service environments vary by facility type or management practices. The fact that two-thirds of participating providers had seen or heard of this practice suggests the percentage of Kenyans impacted is significant. Further, a 2019 paper using nationally representative data for Kenya estimates half of family planning clients in the public sector report being asked to pay a fee for contraceptive commodities despite policies eliminating out-of-pocket expenditures for family planning (Radovich et al. 2019). However, this estimate is based on retrospective client self-reports and the duration of time between the participant's facility visit and their interview may have influenced study results.

Findings from our study contribute to a growing body of literature on informal payment solicitation in East Africa. Participants reported that fees were charged mostly for free family planning methods and services. There was also evidence of more covert methods including drug supply leakage and diverting patients to private medical supplies, which has been previously reported (Maestad and Mwisongo 2011; McPake et al. 1999). The scale of informal payments was found to be quite problematic. Fees ranged from 50 to 3,000 Kenya shillings, which equates to $0.49-29.17$ USD. With nearly 36 percent of Kenyans living under international poverty standards (1.90 USD per day) (Kenya National Bureau of Statistics 2018), such fees may be prohibitive especially for methods that are needed monthly. Variation in the amount of fees solicited appears primarily related to the type of method provided, with long-acting methods securing higher fees. Almost all accounts were of provider rather than patientinitiated payments. Study participants reported fee solicitation is likely to reduce care-seeking behaviors among Kenyans unable to afford such fees and among those Kenyans demoralized by their encounter with a corrupt system, effectively dampening demand for family planning. A recent (2019) qualitative study examined the impact of health financing among those in the lowest wealth quintile in Kenya; participants noted an increased demand for maternal health services after labor and delivery user fees were removed suggesting fees reduce demand for health care services. Study participants noted that the need to survive sometimes 
pushes them to extract payments from very poor clients but did not discuss how they cope with the negative emotions that may arise from such practices (Kabia et al. 2019).

Similar to studies in Tanzania and Ethiopia, we found that inadequate wages were considered a significant contributing factor to solicitation of informal fees from patients (Lindelow and Serneels, 2006; Stringhini et al., 2009). Participants shared comparable sentiments that wages were not reflective of the skill and effort required in order to manage high caseloads and offer a range of health care services. Several participants asserted that providers could not achieve even the most basic needs of food and shelter with current wages, especially among public-sector providers experiencing salary delays from the government. Near the time of data collection, Kenyan doctors and nurses were on strike to protest low wages, salary delays, and unequitable distribution of promotion and training opportunities ('Kenya's nurses strike takes its toll on health-care system" 2017; Makana 2016). For context, in some counties, salary delays were as long as five months (Okech and Lelegwe 2015). In July 2019, near the time of publication, health workers in counties across Kenya were on strike again as a result of salary delays lasting several months (Joe 2019; Ndonga 2019). Medical professionals across all cadres working in Kenyan's public sector earn significantly less than private sector staff (Kenya Institute for Public Policy Research and Analysis 2013). The disparity in public and private sector health care worker wages is common across Sub-Saharan Africa (McCoy et al. 2008). In 2014, the approximate salary for public-sector nurses in the lowest cadre in Kenya ranged from 262 to 335 USD per month, plus allowances for expenses such as housing, transportation, and purchasing uniforms-a 40 percent increase from prior wages that ranged from 187 to 239 USD per month (Jamah 2014). The current minimum wage for civil servants in Kenya is approximately 155 USD per month (Kareithi and Ngetich 2019).

Many participants suggested increased wages could help to eliminate the solicitation of informal fees as would trainings, which offer a monetary benefit. In numerous studies, financial incentives and wage increases have been identified as a necessary but likely insufficient strategy to sustainably improve provider motivation, performance, and retention (Chandler et al. 2009; Willis-Shattuck et al. 2008). In light of these realities, some researchers are exploring the impact of nonfinancial incentives on workforce performance. A recent (2018) study in Tanzania demonstrated that nonmonetary gifts can be an effective means of making large, significant, and lasting improvements to the performance of health care providers (Brock, Lange, and Leonard 2018). This experimental study found worker performance increased by 20 percent during the six-week study period. Peer monitoring has also proven successful in improving provider performance. Clinician's adherence to medical protocols increased significantly and was sustained for 18 months after the implementation of a simple intervention where providers were given expectations for quality of care, encouraged to follow standards, and monitored by peers (Leonard and Masatu 2017). It is possible that the effectiveness of these interventions reflects their ability to shift the intrinsic motivation of providers. Conducting similar studies in Kenya is warranted given the inelastic nature of many of the structural factors mentioned by providers such as widespread corruption.

Participants noted many communities were unaware of their right to receive certain services free of charge and recommended efforts to increase patient knowledge and awareness. Current efforts to inform communities about the price of services have largely fallen short. Simply notifying patients about the price of services may not be sufficient given the covert 
solicitation strategies providers used. More direct community outreach paired with effective feedback mechanisms may better reduce the behavior. A 2007 report by the Federation of Women Lawyers in Kenya similarly found that many patients are unaware of their rights and "a more transparent and effective oversight mechanism" - that is, a mechanism for patient complaints that is accessible, publicized, and leads to visible changes-is needed (Center for Reproductive Rights and Federation of Women Lawyers-Kenya 2007).

A handful of small-scale interventions, implemented primarily in Eastern Europe, have been successful in reducing informal fees, according to a 2010 review (Miller and Vian 2010). In several countries, including Albania, Kyrgyzstan, and Cambodia, efforts were made to formalize fees and increase transparency of the formal fee system through increased signage and posters. In one Albanian hospital, where these efforts were combined with frequent exit interviews and suggestion boxes, utilization of services increased within just one year. In Kyrgyzstan, formalized fees could be retained by the implementing hospital and used to supplement provider salaries, leading to a far more transparent system and increased service utilization. In one Cambodian hospital, a formalized fee schedule led to a 50 percent increase in health care utilization within three years. The authors of the review also suggested that, in some locations, in addition to increased utilization, public confidence in the health system was restored. An older study (1999), conducted in Bolivia, found that the presence of an accessible private sector provider (i.e., competition with the government facility) was associated with a lower likelihood of making an informal payment, as were strategies that promoted the ability of citizens to have a voice in monitoring public service delivery (Gray-Molina, de Rada, and Yañez 2001).

Several limitations must be considered when interpreting the study results. The sample was limited to two large cities in Kenya. The scope and contributors to informal payments may differ across geographic location. Further, given the illegal nature of the behavior, it is possible that some providers were not as comfortable admitting the practice occurs. Finally, this study utilizes a qualitative study design, with purposeful sampling techniques allowing for information-rich cases. This study design necessarily limits statistical generalizability. However, the primary findings that informal payments in Kenya are underpinned by institutional-level issues such as infrequent supervision and low wages resonates with a larger body of literature on other negative provider behaviors such as provider absenteeism and disrespectful client treatment.

\section{CONCLUSION}

The solicitation of informal payment in Kenyan health care facilities is a complex behavior motivated by individual and structural factors. Low wages coupled with under-informed patients and senior officials also engaging in the practice allows providers to continue charging patients unsanctioned fees. Understanding the nature and determinants of the behavior provides useful information for the development of culturally relevant and sustainable interventions such as patient education, effective mechanisms for patient feedback, and increasing provider motivation via financial and nonfinancial incentives. More research is needed to assess the scope of informal payments on a national or subnational level, to estimate the 
prevalence of informal payments with innovative methods, and to gain insight from key stakeholders on the feasibility and suitability of potential interventions to reduce this practice.

\section{REFERENCES}

Balabanova, Dina, and Martin McKee. 2002. "Understanding Informal Payments for Health Care: The Example of Bulgaria." Health Policy 62(3): 243-73. http://doi.org/10.1016/S0168-8510(02)00035-0.

Braun, Virginia, and Victoria Clarke. 2006. "Using Thematic Analysis in Psychology.” Qualitative Research in Psychology 3(2): 77-101.

Brock, J. Michelle, Andreas Lange, and Kenneth L. Leonard. 2018. "Giving and Promising Gifts: Experimental Evidence on Reciprocity from the Field.” Journal of Health Economics 58: 188-201.

Center for Reproductive Rights and Federation of Women Lawyers-Kenya. 2007. Failure to Deliver: Violations of Women's Human Rights in Kenyan Health Facilities. Kenya: Center for Reproductive Rights and Federation of Women Lawyers.

Chandler, C. I., S. Chonya, F. Mtei, H. Reyburn, and C. J. Whitty. 2009. "Motivation, Money and Respect: A MixedMethod Study of Tanzanian Non-Physician Clinicians.” Social Science \& Medicine 68(11): 2078-88. https://doi.org/10.1016/ j.socscimed.2009.03.007.

Ensor, Tim. 2004. "Informal Payments for Health Care in Transition Economies." Social Science \& Medicine 58(2): 237-46. http://doi.org/10.1016/S0277-9536(03)00007-8.

Gaal, Peter, Paolo Carlo Belli, Martin McKee, and Miklos Szocska. 2006. "Informal Payments for Health Care: Definitions, Distinctions, and Dilemmas." Journal of Health Politics, Policy and Law 31(2): 251-93.

Government of Kenya. 2017. “Family Planning 2020 Commitment.” http://www.familyplanning2020.org/sites/default/files/ Kenya_FP2020_Commitment_2017_1.pdf. (accessed November 06, 2019).

Gray-Molina, George, E. Perez de Rada, and Ernesto Yañez. 2001. "Does Voice Matter? Participation and Controlling Corruption in Bolivian Hospitals.” In Diagnosis Corruption Fraud in Latin America's Public Hospitals Di Tella, R., Savedoff, W. D., 26-56. Washington, D.C.: Inter-American Development Bank, 2001.

Jamah, Ally. 2014. "New Pay and Allowances for Kenya Nurses." Standard Digital, October 3, 2014. https://www. standardmedia.co.ke/article/2000140276/new-pay-and-allowances-for-kenya-nurses.

Joe, Ojwang. 2019. "Health Workers Shun Kisumu County Hospitals as July Pay Stalemate Persists.” Capital News, August 19, 2019. https://kenya-news-alerts.com/health-workers-shun-kisumu-county-hospitals-as-july-pay-stalemate-persistscapital-news/.

Kabia, Evelyn, Rahab Mbau, Robinson Oyando, Clement Oduor, Godfrey Bigogo, Sammy Khagayi, and Edwine Barasa. 2019. "“We are Called the Et Cetera": Experiences of the Poor with Health Financing Reforms that Target Them in Kenya." International Journal for Equity in Health 18(1): 98. https://doi.org/10.1186/s12939-019-1006-2.

Kareithi, Amos, and Jacob Ngetich. 2019. "Civil Servants Set for Salary, Grades Review in New Scheme.” Standard Digital, July 6, 2019. https://www.standardmedia.co.ke/business/article/2001332758/new-salary-review-and-grades-for-civil-servants.

Kenya Institute for Public Policy Research and Analysis. 2013. A Comparative Study on Public-Private Sector Wage Differentials in Kenya. Nairobi, Kenya:KIPRA.

Kenya National Bureau of Statistics. 2018. Basic Report on Well-Being in Kenya: Based on the 2015/16 Kenya Integrated Household Budget Survey (KiHBs). Nairobi, Kenya:Kenya National Bureau of Statistics.

Kenya National Bureau of Statistics, and ICF International. 2015. Kenya Demographic and Health Survey 2014. Nairobi, Kenya: Kenya National Bureau of Statistics, and ICF Internationa

"Kenya's nurses strike takes its toll on health-care system." 2017. Lancet 389(10087): 2350. https://doi.org/10.1016/s0140 $-6736(17) 31661-6$.

Killingsworth, James R., Najmul Hossain, Yuwa Hedrick-Wong, Stephen D. Thomas, Azizur Rahman, and Tahmina Begum. 1999. "Unofficial Fees in Bangladesh: Price, Equity and Institutional Issues." Health Policy and Planning 14(2): 152-63.

Leonard, K. L., and M. C. Masatu. 2017. “Changing Health Care Provider Performance through Measurement.” Social Science \& Medicine 181: 54-65. https://doi.org/10.1016/j.socscimed.2017.03.041. 
Lewis, Maureen. 2007. "Informal payments and the financing of health care in developing and transition countries." Health Affairs 26(4): 984-97.

Lindelow, M., and P. Serneels. 2006. “The Performance of Health Workers in Ethiopia: Results from Qualitative Research.” Social Science \& Medicine 62(9): 2225-35. https://doi.org/10.1016/j.socscimed.2005.10.015.

Lindkvist, I. 2013. "Informal Payments and Health Worker Effort: A Quantitative Study from Tanzania." Health Economics 22(10): 1250-71. https://doi.org/10.1002/hec.2881. https://www.ncbi.nlm.nih.gov/pubmed/23188621.

Maestad, O., and A. Mwisongo. 2011. "Informal Payments and the Quality of Health Care: Mechanisms Revealed by Tanzanian Health Workers.” Health Policy 99(2): 107-15. https://doi.org/10.1016/j.healthpol.2010.07.011.

Makana, Fred. 2016. “Details of the Disputed Salary Deal Signed by Kenyan Doctors and Nurses.” Standard, December 5, 2016. https://www.standardmedia.co.ke/article/2000225884/details-of-the-disputed-salary-deal-signed-by-kenyan-doctorsand-nurses.

McCoy, David, Sara Bennett, Sophie Witter, Bob Pond, Brook Baker, Jeff Gow, Sudeep Chand, Tim Ensor, and Barbara McPake. 2008. "Salaries and Incomes of Health Workers in Sub-Saharan Africa." The Lancet 371(9613): 675-81. https://doi.org/10.1016/s0140-6736(08)60306-2.

McPake, Barbara, Delius Asiimwe, Francis Mwesigye, Mathias Ofumbi, Lisbeth Ortenblad, Pieter Streefland, and Asaph Turinde. 1999. "Informal Economic Activities of Public Health Workers in Uganda: Implications for Quality and Accessibility of Care." Social Science \& Medicine 49(7): 849-65. http://doi.org/10.1016/S0277-9536(99)00144-6. http://www.sciencedirect.com/science/article/pii/S0277953699001446.

Miller, Kelly, and Taryn Vian. 2010. "Strategies for Reducing Informal Payments.” Anticorruption in the Health Sector: Strategies for Transparency and Accountability. Sterling, VA: Kumarian.

Moldovan, Andrada, and Steven Van de Walle. 2013. “Gifts or Bribes?” Public Integrity 15(4): 385-402. https://doi.org/ 10.2753/PIN1099-9922150404.

Ndonga, Simon. 2019. "Strike Looms in 24 Counties over Unpaid July Salaries as Revenue Standoff Persists.” Capital News, August 13, 2019. https://www.capitalfm.co.ke/news/2019/08/strike-looms-in-24-counties-over-unpaid-july-salaries-asrevenue-standoff-persists/.

Okech, Timothy Chrispinus, and Steve Ltumbesi Lelegwe. 2015. "Analysis of Universal Health Coverage and Equity on Health Care in Kenya.” Global Journal of Health Science 8(7): 218-27. https://doi.org/10.5539/gjhs.v8n7p218.

Radovich, Emma, Mardieh L. Dennis, Edwine Barasa, Francesca L. Cavallaro, Kerry L. M. Wong, Josephine Borghi, Caroline A. Lynch, Mark Lyons-Amos, Timothy Abuya, and Lenka Benova. 2019. "Who Pays and How Much? A CrossSectional Study of Out-of-Pocket Payment for Modern Contraception in Kenya." BMJ Open 9(2): e022414. https://doi.org/ 10.1136/bmjopen-2018-022414.

Stringhini, Silvia, Steve Thomas, Posy Bidwell, Tina Mtui, and Aziza Mwisongo. 2009. "Understanding Informal Payments in Health Care: Motivation of Health Workers in Tanzania.” Human Resources for Health 7(1): 53. https://doi.org/ 10.1186/1478-4491-7-53.

Tumlinson, Katherine, Ilene S. Speizer, Linda H. Archer, and Frieda Behets. 2013. "Simulated Clients Reveal Factors that May Limit Contraceptive Use in Kisumu, Kenya." Global Health: Science and Practice 1(3): 407-16. https://doi.org/ 10.9745/ghsp-d-13-00075.

Willis-Shattuck, M., P. Bidwell, S. Thomas, L. Wyness, D. Blaauw, and P. Ditlopo. 2008. "Motivation and Retention of Health Workers in Developing Countries: A Systematic Review.” BMC Health Services Research 8: 247. https://doi.org/ $10.1186 / 1472-6963-8-247$.

\section{ACKNOWLEDGMENTS}

This work was supported by a career development grant (R00 HD086270) to the lead author and an infrastructure grant for population research (P2C HD047879) to the Carolina Population Center at the University of North Carolina at Chapel Hill. The Eunice Kennedy Shriver National Institute of Child Health and Human Development (NICHD) of the National Institutes of Health (NIH) awarded both of these grants. The contents of this article are solely the responsibility of the authors and do not necessarily represent the official views of the NIH/NICHD. 